\title{
COMMUNITY-LED LOCAL DEVELOPMENT THROUGH LAG "GALABOVO-OPAN" - ACHIEVEMENTS AND CHALLENGES
}

\author{
St. Tsacheva \\ PhD student, Faculty of Economics, Trakia University, Stara Zagora, Bulgaria
}

\begin{abstract}
The study follows and analyzes the work of LAG "Galabovo-Opan", the objectives achieved by the organization, and the results obtained during the implementation of the Strategy for Community-led Local Development within the Programme "Rural Development" for 2016-2019.

The object of this report is the activity of local communities for the development of the strategy, the formation of expert groups, the selection of potential beneficiaries and building capacities for its implementation in two municipalities from the region of Stara Zagora. The two municipalities have a different profile with respect to economic branches - highly developed mining industry and energetics in Galabovo Municipality and predominant agriculture in a municipality comprised by villages, such as Opan Municipality.

We have also included the more important projects realized by LAG "Galabovo-Opan" for the above mentioned period.
\end{abstract}

Key words: Local Action Groups (LAGs), local development of municipalities

\section{INTRODUCTION}

LEADER is an innovative approach within the framework of EU policies for developing rural regions. The name LEADER comes from the French acronym for "Liaison Entre Actions de Développement de l'Économie Rurale", meaning 'Links between the rural economy and development actions'. The difference between LEADER and the other more traditional political measures for the development of rural regions lies in the direction of "how" to act, instead of "what" needs to be done.

LEADER- seven distinctive features:

1. Territorial approach - development of a strategy for local development which takes into accounts the strengths and weaknesses of a certain territory and determines competitive advantages.

2. Bottom-up approach - the most distinctive feature of the LEADER. Local people participate in decision-making for the strategy and the choice of priorities which must be followed.

3. Public-private partnership.
4. Innovations - unexplored, neglected or underestimated resources are developed by using local resources.

5. Integrated and multisector activities.

6. Network collaboration - stimulates the exchange of knowledge and practices between LAG and rural areas.

7. Projects for collaboration in and outside the country.

Some of the characteristics of LAG can be distinguished on the basis of the seven features of the LEADER approach. The LEADER approach is based regionally, therefore LAGs are "miniature regions" (Lukesh 2007 [1]).

The LEADER programme aims to unite the insufficient and unevenly distributed human, financial, natural and other resources in rural regions. Attracting local people is one of the major pillars of LEADER and local action groups play a key role for stimulating the development of the territory, not just administrating it (Dubost 2008 [2]).

LEADER is implemented by about 2800 local action groups (LAGs) covering 61\% of the rural population in the EU (situation as of end 
2018). During the programme period 20142020 the LEADER method has been extended under the broader term Community-led Local Development (CLLD) to three additional EU funds: the European Maritime and Fisheries Fund (EMFF), the European Fund for Regional Development (EFRD) and the European Social Fund (ESF).

For the application of the CLLD approach the Programme "Rural Development" (PRD) has allocated $5 \%$ of its budget. The funds from ESF and EFRD for implementing CLLD also amount to $5 \%$ of the allocated funds from the operational programmes: Operational Programme for Innovation and Competitiveness (OPIC), Operational Programme for Human Resources Development (OPHRD), Operational Programme for Science and Education for Smart Growth (OPSESG), Operational Programme "Environment" (OPE).

The funding of fisheries local action groups (FLAGs) amounts to $18 \%$ of the EMFF, whereas LAGs and FLAGs simultaneously applying multifund strategies cannot coexist on the same territory. (EU structural funds, Programme "Rural Development" 2014-2020) [3].

Sixty LAGs were established within the country under the following financial conditions:

- On-going costs for administration, skills acquisition, awareness and publicity $-25 \%$ from the budget of the Strategy for Local Development within the Programme "Rural Development";

- Correlation between the administration costs and the skills acquisition and publicity costs $-80 / 20$.

- Advance payment for $50 \%$ from the costs for administration, skills acquisition, awareness and publicity.
What is a Local Action Group?

Local Action Group is a non-profit legal entity with public benefit purposes registered under the Law for non-profit legal entities. It represents a public-private partnership with mandatory participation of the municipality or the municipalities on the territory officiated by the LAG in the collective supreme organ.

\section{METHODOLOGY}

The focus of the present study is a Local Action Group and its strategy for tackling the problems of the community in two municipalities from the region of Stara Zagora - Galabovo and Opan.

The leading research approach of the study is monographic, combined with in-depth interview with part of the managing team of the LAG and several project applicants.

SWOT analysis (analysis of the strengths, weaknesses, opportunities and threats facing LAG and the beneficiaries) has also been applied.

\section{RESULTS}

The territory of LAG "Galabovo-Opan" comprises two municipalities - Galabovo and Opan, which are a part of the region of Stara Zagora in the South-East planning region. Galabovo Municipality consists of 11 living areas - the town of Galabovo and ten adjacent villages. Opan Municipality is one of the 47 municipalities in Bulgaria where the living areas are exclusively villages -13 , including the municipal centre - the village of Opan. According to data, from the National Statistical Institute towards 31 December 2019, Galabovo municipality ranks sixth in the region in terms of population reaching a total of 11372 , whereas Opan municipality is last with 2410 inhabitants. The population on the territory of the LAG is 13 781 (National Statistical Institute, statistical data for 2019 [4]). (Table 1 and 2)

Table 1. Changes in the number of population 2010, 2014 u 2019

\begin{tabular}{|l|l|l|l|}
\hline Number of people & 2010 & 2014 & 2019 \\
\hline Galabovo & 14086 & 12668 & 11371 \\
\hline Opan & 3497 & 2703 & 2410 \\
\hline
\end{tabular}

The geographic location of the region is one of its biggest advantages. The climatic conditions are favorable for agriculture and livestock breeding. The waters on the territory of Galabovo Municipality are formed mostly by the Sazlijka River and its left tributaries - the Ovcharitsa river and the Sokolitsa river, whereas the three rivers are used for irrigation. The municipality uses the resources of two larger and 41 micro-dams. The Rozov Kladenets dam is unique for its biological diversity - the 65 species of birds which gather there, are an interesting object for observation. 
An important resource for the municipality is the existing mineral source in the village of Trakia. The water meets the requirements for resort and recreation purposes, bottling of natural waters and the production of soft drinks.

Table 2. Dynamics in the number of population in $\%$

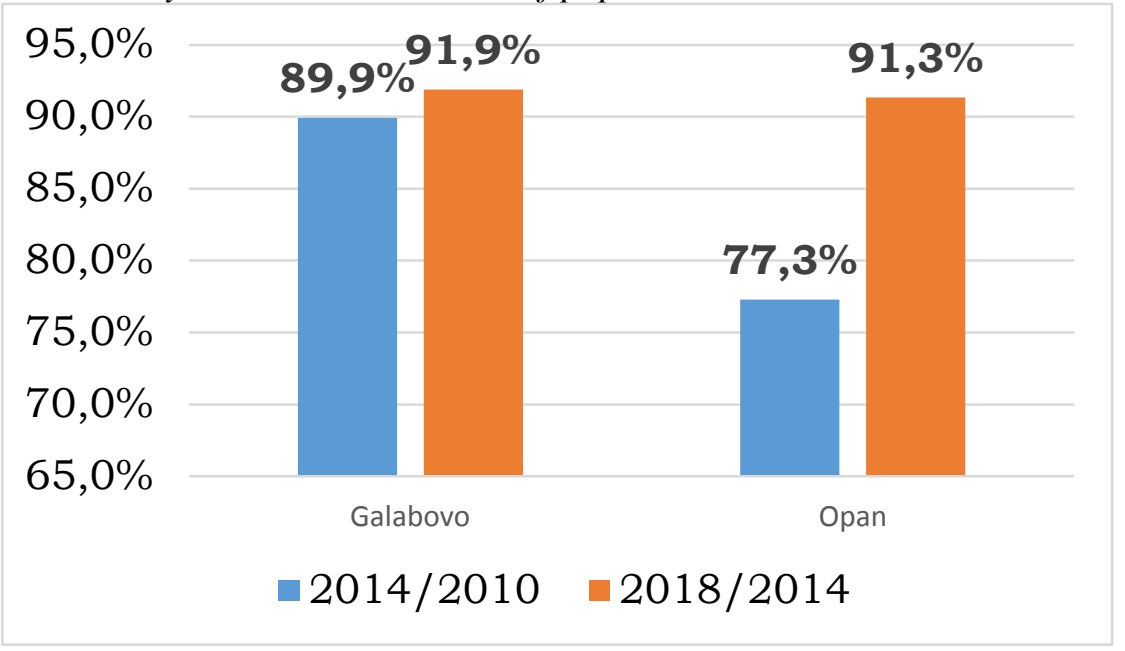

The main raw resource is lignite and most of the extraction areas are situated in Galabovo Municipality. They are foundational for the leading economic branches - coal mining and electricity production. Galabovo Municipality has serious positions in lignite mining within the framework of the Eastern Maritsa coal basin. It spreads over $240 \mathrm{~km}^{2}$ and comprises $57 \%$ of the coal reserves of Bulgaria.

The area of the LAG includes several zones and territories protected by different EU directives - four in Galabovo Municipality and two in Opan Municipality.

LAG "Galabovo -Opan" is located in a region with existing cultural and historical heritage, yet unfortunately its potential has not been preserved and used satisfactorily.

The two municipalities of LAG "GalabovoOpan" have a different profile with respect to their economic branches. Leading economic sectors for Galabovo are the extraction industry, electricity production, briquettes and repair parts and services for the energetics sector. Agriculture comes second in importance.

The main economic branch of Opan Municipality is agriculture which has also stimulated the development of the food industry in recent years. The biggest share belongs to micro-enterprises, comprising $94.4 \%$ of the economically active companies in the municipality - predominantly with an agricultural profile. (Table 3 and 4)

Table 3. Changes in the number of enterprises:

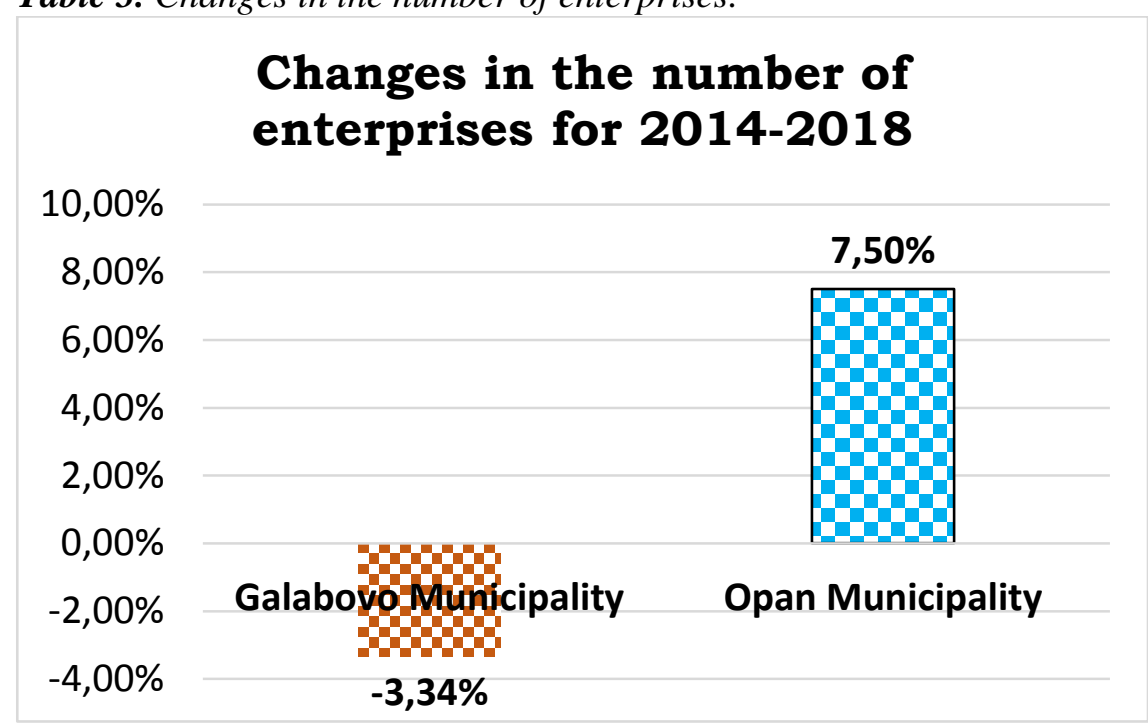


Table 4. The employment-unemployment levels of the two municipalities are also different.

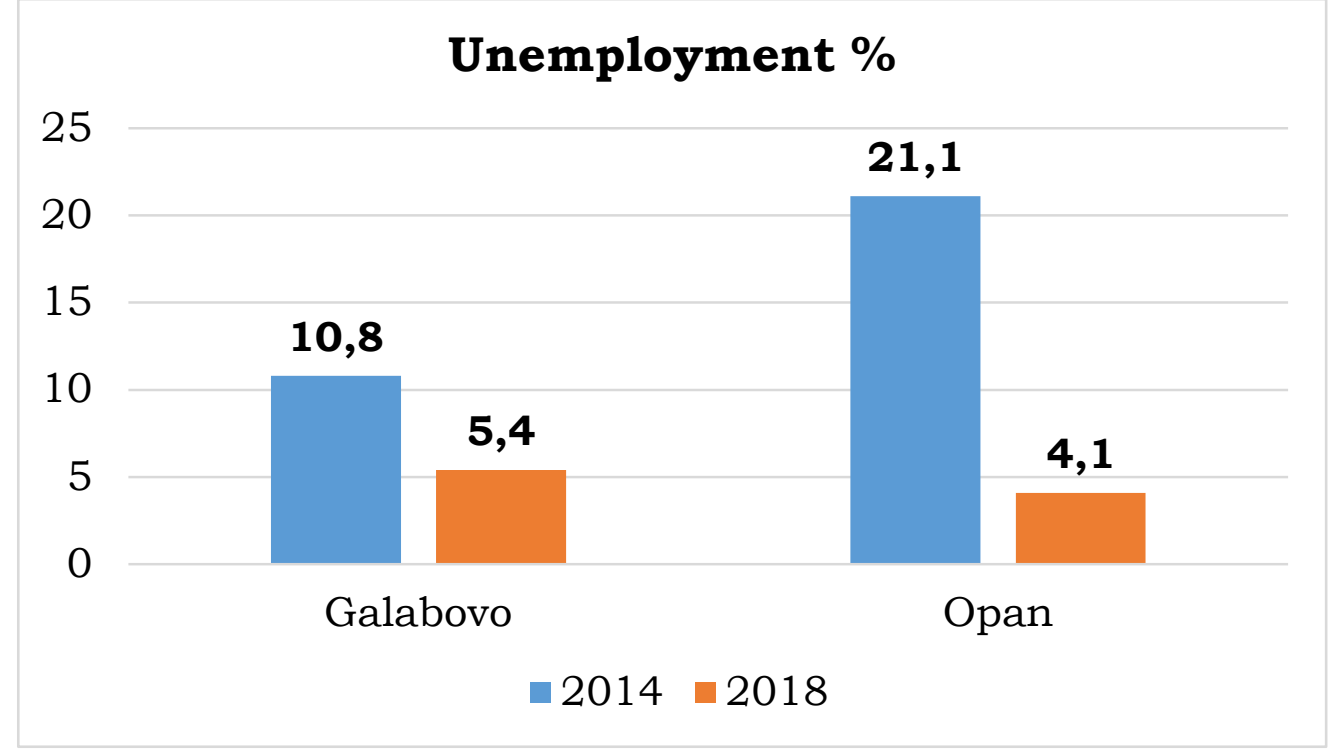

The people employed in Galabovo Municipality are $85.1 \%$ of the economically active population, whereas the highest share of employees works in electricity production and coal mining. The average annual salary is 15 $305 \mathrm{BGN}$, which reaches the average for the country.

The employees in Opan Municipality are largely in the agricultural sector $-39.4 \%$, the average annual salary is 5572 BGN, which ranks the municipality at the penultimate place in the region.

For both municipalities of this LAG the major issue on the labour market, apart from the demographic crisis is the lack of education and qualified labour.

Common issues for this territory are the high share of women entering the labour market, and the high number of unemployed youth, despite the prevailing tendency for decrease. Most vulnerable to unemployment are persons without a specialty or low education.

One of the biggest advantages of the territory of LAG "Galabovo-Opan" is its good location in the transport infrastructure of the country. First-class domestic and international roads pass in the vicinity, and the EU transport corridors 4,8 and 9 crosses here. The region is transversed by two freeways - Maritsa and Trakia, the first-class roads E80, E85, and E773 and the meridian highways connected to the EU corridors 10 and 7. The transport network of Galabovo Municipality takes up $1412 \mathrm{~km}^{2}$ and is represented by a republican and municipal road network, where the length of the republican roads is $47.2 \mathrm{~km}$, and the municipal $-29.8 \mathrm{~km}$.

Opan Municipality is regarded as an underdeveloped rural region characterized by a low degree of development of the transport and technical infrastructure. The area of the road infrastructure is $1739 \mathrm{~km}^{2}$, of which $48.6 \mathrm{~km}$ are republican roads, and $33.3 \mathrm{~km}$ - municipal roads, the larger part of which needs major repair works.

All living areas on the territory of the LAG have electricity and are part of the energy network of the country.

Both municipalities of the LAG have water supply systems to all inhabited areas where potable water is delivered. The sewage system, however, is not well-developed, whereas a sewage network exists practically only in the municipal centres - the town of Galabovo and partially in the village of Opan. The lack of sewage system in the other villages is a serious problem. One of the priorities for the development of the municipal infrastructure during the planned period 2014-2020 is namely the building of a sewage system.

In Galabovo Municipality the social services system is well developed and is provided in several types - the Senior People Home, the Protected House in the village of Aprilovo, Daycare Centre for Children and Youth with Disabilities, Home Social Care and Public Kitchen, Personal Assistant, Pensioner Clubs in all living areas, Invalid's Club. 
In Opan Municipality some social services are offered, and the main challenges are related to the senior people living alone, low-income pensioners, who cannot care for themselves. At present, the municipality offers the services of "Home social care" and plans to build a Daycare Centre for Senior People.

With respect to the environmental conditions and the ecological hazards the two municipalities covered by the LAG "Galabovo-Opan" differ drastically.

Galabovo Municipality has been known for years for its ecological problems, and it has been named an ecological hotspot. Part of these problems have found a solution in the last 10 years for which the municipal administration has played a leading role, however, the implementation and financing of the events are exercised by enterprises and companies working on this territory. Opan Municipality is among the rural regions of the country where the lack of large industrial enterprises does not lead to significant environmental problems.

The groups of stakeholders who can initiate and benefit from funding on the territory of the LAG are: Galabovo and Opan Municipalities, agricultural producers and cooperatives, trade companies with various activities, culture centres and NGOs, hotels, catering establishments and artisans.

During the large scale awareness campaign representatives of the following groups expressed an interest in the LAG's activity: the public sector, represented by personnel from Galabovo and Opan Municipalities, the NGO sector with representatives from culture centres and sports clubs, economic sector represented by agricultural producers, stock breeders, merchants, transport entrepreneurs, persons employed in the services sector, etc. (LAG "Galabovo-Opan", Strategy for Development [5])

\section{SWOT analysis:}

Strengths

- Good location - the territory of LAG is situated in the centre of Bulgaria and is a cross-section of first-class domestic and international transport connections

- Favorable natural resources for developing the economy and agriculture

- High share of arable land in both municipalities
- Presence of mineral deposits and developed heavy industry in Galabovo Municipality enterprises of national importance

- Sustainable employment of the population in the Maritsa-Iztok complex

- Developed partnership municipalityelectricity plants on the territory of Galabovo Municipality

- Good coverage of mobile services in both municipalities

- A well-developed system of social care in Galabovo Municipality

- Local authorities create active programmes for support and integration of socially disadvantaged and minority groups

- Preserved historical and cultural traditions; presence of monuments of cultural heritage, especially in Opan Municipality; rich cultural calendar, related to local traditions and community in both municipalities

- Large businesses on the territory of Galabovo Municipality try to reduce the negative effects on the environment

- The lack of big polluters in Opan Muicipality - on its territory there are no industrial enterprises, nor Thermal Electric Plant.

\section{Weaknesses}

- Small areas of land ownership; growing mostly cereal and technical crops and, therefore, a small number of employed personnel in this branch.

- Impact of the mining industry on the land resources in Galabovo Municipality; disturbing the balance of the existing land fund.

-Weak local small business; lack of processing enterprises for agricultural production

- Livestock breeding is developed in privately owned holdings on an extensive principle in both municipalities.

- Continuous trend of a decrease in the number of the population; aging, migration of young people, increase of the minority population

- Bad road infrastructure between the living areas; unsatisfactory state of the street network; insufficient financial resources for the maintenance and repair of municipal roads

- Lack of sewage system

- Difficult access of patients in villages to specialized medical care 
- Uneven territorial distribution of medical practices

- Reduction in the number of children in schools; concentration of schools and kindergartens in municipal centres

- Bad quality of air in both municipalities, especially in Galabovo Municipality

- Old waste collection equipment

- Insufficient use of the cultural heritage and the natural resources and their transformation into a possibility for developing tourism

\section{Opportunities}

- Development of productions accompanying leading industrial branches; potential for enterprises for processing agricultural produce and modernization of rural holdings

- Utilization of EU funds with the purposes of developing SMEs, provided mostly by the Program "Rural Development" for developing agriculture.

- Policy development for demographic stabilization, creation of new jobs, especially for women; creating conditions for retaining the population in the municipality through development and implementation of programmes and projects; taking measures to improve the qualification of the unemployed.

- Potential for public-private partnerships in the social sphere; building sewage systems in rural areas

- Developing alternative tourism, creating sustainable touristic products; opening, preserving, presenting and advertising new cultural historical objects on the territory of LAG;

- Improving the environmental conditions, especially in Galabovo Municipality - work on green projects aiming to tackle ecological hotspots.

\section{Objectives for LAGs:}

Dynamically developing territory with effective economy, harmonious living environment and conditions for fulfilling expression of people's capacities.

In this sense, two priorities have been formulated:

Priority 1: Providing sustainable economic development of the agricultural sector on the basis of increasing competitiveness of the sector and the viability of holdings; to fulfill these objectives the following measures have been taken: Measure 4.1. "Investment in agricultural holdings", and Measure 4.2. "Investment in processing/marketing of the agricultural products".

Priority 2: Improving the quality of life on the territory through diversification of the possibilities for employment, improvement of the image of the living areas and enhancing the natural and cultural traditions of the local community. This specific goal has been realized through Measure 6.4. "Investment support for non-agricultural activities" and Measure 7.2. "Investment in the creation, improvement and extension of all types of small scale infrastructure".

The protection of the environment, rural landscape and local identity will be achieved through the innovative Measure 7.1. "LAG Galabovo-Opan territory unites us".

The innovativeness of the CLLD strategy may be found in the included new approaches, methods and means for its implementation which have not been applied on the territory of the local community through:

Evaluation criteria for projects according to Measures 4.2. "Investment in the processing/marketing of agricultural products", and 6.4. "Investment support for nonagricultural activities" - where the possibilities for creating a new product or service for the territory have been evaluated.

Measure 7.1. "LAG Galabovo-Opan territory unites us" - additional innovative measure which offers the possibility for using natural resources in forms innovative for the territory of LAG.

In the evaluation criteria for projects under Measure 7.2. "Investment in the creation, improvement or extension of all types of small scale infrastructure, including investment in RES energy and saving energy" the new methods and/or ways to tackle local problems and weaknesses on the territory have been evaluated.

Financial justification of the budget the distribution of means by programmes and measures:

The analysis of the needs for restructuring and modernization of agricultural holdings and enterprises on the territories of LAG "Galabovo-Opan" shows that $25 \%$ of the total 
public contribution of CLLD was allocated to Priority 1 , and $75 \%$ went to Priority 2 . In order to satisfy the needs for improvement of the efficiency of agricultural holdings and to encourage the development of processing industry $25 \%$ of the budget for the Strategy was allocated to Measure 4 "Investment in material assets" within the Programme "Rural Development", whereas the means for the two sub-measures 4.1. and 4.2. were respectively 528074 BGN и 205362 BGN.

With respect to diversifying economic activities and increasing employment on the territory of LAG $35 \%$ of the funds of the Strategy of LAG were allocated to Measure 6 "Development of holdings and enterprises" from the Programme "Rural Development", whereas the means for sub-measure 6.4. were 1 026811 BGN.

In order to improve the living conditions in rural areas and to protect the environment and local identity $40 \%$ of the Strategy of LAG were allocated to Measure 7 "Main services and renovation of villages in rural regions" of the Programme "Rural Development", whereas the money flow to sub-measures 7.2. and 7.1. was respectively $1056148 \mathrm{BGN}$ and 117350 BGN.

Originally, LAG started receiving projects under Measure 4 "Investment in material assets" and afterwards continued its work under Measure "Development of holdings and enterprises", sub-measure 7.1. "LAG Galabovo-Opan territory unites us" and submeasure 7.2. "Investment in the creation, improvement or extension of all types of small scale infrastructure, including investment in RES energy and saving energy".

\section{First signed agreements}

LAG "Galabovo-Opan" has signed agreements for providing grants under the call BG06RDNP001-19.068-S1, LAG GalabovoOpan, sub-measure 4.1. "Investment in agricultural holdings".

By an Ordinance № 03 - RD/579 from 19.02.2020 of the Executive Director of State Fund "Agriculture" Vasil Grudev, all project proposals for the call approved by LAG were confirmed, and six projects were included in the reserves list. According to the control excerpt related to article 60, paragraph1 of Ordinance № 22 from 14.12.2015 the project proposals BG06RDNP001-19.068-0012
"Purchase of agricultural equipment for the needs of Agricultural Holding Agrolink OOD" by Agrolink OOD, and BG06RDNP00119.068-0014 "Modernization of a dairy farm in the village of Vasil Levski, Opan Municipality" by Isian EOOD were reviewed and approved by the State Fund "Agriculture". On 19.03.2020 the Chairman of the Managing Board of LAG "Galabovo-Opan" eng. Plamen Barakov signed the first administrative agreements for allocating grants within the Programme "Rural Development" for 20142020, co-financed by the European Agricultural Fund for Rural Development.

The project proposal of Isian EOOD includes activities for the modernization of a dairy farm related to the purchase of a central milk pipeline for mechanical milking of animals, diesel generator for independent power supply for the farm, as well as agricultural machinery to be used for baling and foliation of hay (alfalfa, grassland and meadows) and straw from cereal crops entirely for the purposes of the livestock breeding facility.

The project proposal of Agrolink OOD includes the purchase of two seeders to be used by the farm. The value of the project is 255 $336.60 \mathrm{BGN}$, and the grant covers $50 \%$ of the approved costs.

\section{CONCLUSIONS}

From the performed analyses we have found that the main problems on the territory of LAG "Galabovo-Opan" are the state of infrastructure (water and land), unemployment and social services, and the lack of sufficient investment.

Problematic areas are ecology, demographics (youth migration, aging population), waste collection and cleanliness, lack of fresh investment and capital, insufficiently developed financial services, etc.

The potential for the development of the territory is in the further growth of land farming through modernization of holdings, both as administration, and as technical availabilities. This will assist the creation of processing industry with a perspective for the realization of production both on the local, and the international markets.

Big possibilities for development lie ahead for non-agricultural activities in the services and trade sector. 
A very large potential is seen in the cultural and historical heritage of the two municipalities - a sphere which has not been sufficiently exploited, except for folklore celebrations.

The archeological and historical monuments, as well as biological diversity represent an undeveloped territory for future investment, jobs, and sustainable development.

LAG "Galabovo-Opan" has the potential to use the opportunities for a broader participation in projects such as "Partnership for Rural Europe" (PREPDRE), the initiatives of the association "National Rural Network", etc. and follow the experience of Hungary, Sweden, Slovakia, Poland, etc. (Stoyanova Z. 2011 [6]).

\section{REFERENCES}

1. Lukesh, R. 2007. LAG-Handbook. A Guide through the Stunning World of Local Action Groups.

2. Dubost M.,2008

3. EU Structural Funds. Programme "Rural Development" 2014-2020

4. National Statistical Institute, statistical data for 2019

5. LAG "Galabovo-Opan", Strategy for Development

6. Stoyanova, Z. 2011. Local Action Groups in Bulgaria - Problems, Possibilities, Perspectives (in Bulgarian) 